\title{
Insurance approval of mesenchymal stem cell for acute GVHD in Japan: need of follow up for some remaining concerns
}

\author{
Koichi Miyamura ${ }^{1}$
}

Received: 14 December 2015 / Accepted: 15 December 2015 / Published online: 12 January 2016

(C) The Japanese Society of Hematology 2016

\begin{abstract}
Acute graft-versus-host disease (aGVHD) is a major obstacle following allogeneic hematopoietic stem cell transplantation. Steroid is the standard treatment for aGVHD grade II-IV; however, nearly half of patients do not respond to the therapy. Many drugs have been proposed, but no standard therapy has been determined. This is because of the resistance to these drugs and of infections due to prolonged immunosuppressive states. Over the past decade a new approach using mesenchymal stem cells (MSCs) has been emerging in Japan and western countries. MSCs have unique characteristics such as specific immunosuppressive properties, no immunogenicity on their own and supportive activity for hematopoiesis. Most of the published trials have reported a favorable effect in acute GVHD, but a phase III trial failed to reach the primary endpoint, although, subgroup analyses found significant effects on gut and liver GVHD in the patients with MSCs infusion. In Japan several institutes are trying to develop MSC for clinical use in post HSCT patients. However, several limitations make it difficult to use MSC in clinical practice. Recently we conducted a phase II/III study using MSC (JR-031) for patients with steroid-refractory grade III or IV aGVHD. From the feasible clinical results, JR-031 was approved by PMDA as the first product which meets the Act to Revise the Pharmaceutical Affairs Act and the Act to Ensure the Safety of Regenerative Medicine. The cost of one series of the treatment is more than ten million yen. Now we encounter new issues such as cost, indication, safety and efficacy. The mechanism of MSC is still unclear
\end{abstract}

Koichi Miyamura

miyamu@ nagoya-1st.jrc.or.jp

1 Department of Hematology, Japanese Red Cross Nagoya First Hospital, Nagoya, Japan and potential concerns about ectopic tissue formation and MSC related malignancy in vivo remain. In conclusion, MSC infusions are well tolerated and show benefit in some patients without adverse safety effects; however, long-term follow-up is needed to be more certain of this.

Keywords Mesenchymal stem cell - Graft-versus-host disease $\cdot$ Safety $\cdot$ Cost $\cdot$ Follow-up

\section{Introduction}

Allogeneic hematopoietic stem cell transplantation (AlloHSCT) is a curative therapeutic option for hematopoietic malignancies and hematopoietic stem cell disorders [1]. Graft-versus-host disease (GVHD) is a major obstacle following allogeneic HSCT. Acute GVHD (aGVHD) develops in a significant number of patients who receive Allo-HSCT despite GVHD prophylaxis [2]. Once aGVHD grade IIIV develops, standard initial therapy is systemic administration of methylprednisolone. However, about half of the patients do not respond to this therapy [3, 5]. Despite nearly 40 years of clinical experience and developing new agents, the treatment of steroid refractory aGVHD still needs to be improved [6-20]. Hitherto no standard strategy has been established [4].

Mesenchymal stem cells (MSCs) were originally identified in mouse bone marrow and were well characterized for their multi-potentialities [19]. Recent studies have shown that MSCs are a strong modulator of both acquired and natural immune systems. Thus, MSCs would seem to be promising for the treatment of excessive immune responses.

Since the first results of dramatically improvement with treatment using BM-MSCs in a 9-year-old boy with refectory GVHD, there have been several reports on the 
effectiveness of MSCs against steroid refractory aGVHD [20-39]. In Japan, several institutes have carried out clinical studies of MSCs for complications after HSCT. Previously, we reported a phase I/II study using MSCs (JR-031) derived from bone marrow of unrelated healthy subjects for patients with steroid-refractory grade II or III acute GVHD [40]. Subsequently, we conducted a phase II/III study using JR-031 for patients with steroid-refractory gradeIII or IV acute GVHD [41]. From the feasible clinical results, JR-031 was approved by PMDA as the first product which meets the Act to Revise the Pharmaceutical Affairs Act and the Act to Ensure the Safety of Regenerative Medicine.

Now we encounter old and new concerns such as cost, indication, safety and efficacy. In this review, I will discuss the current status of MSC treatment and future direction of cell therapy.

\section{Mesenchymal stem cell}

MSCs and MSC-like cells can be isolated from many different tissues, including bone marrow, adipose tissue, placenta, amniotic fluid, and umbilical cord blood [19]. All MSCs are phenotypically and functionally equivalent, and it is not known how in vitro expansion affects these features. MSCs have unique characteristics, such as specific immunosuppressive properties, no immunogenicity, and supportive activity for hematopoiesis. MSCs are thought to accumulate at injury sites and help to repair them. MSCs have strong immunosuppressive actions on many kinds of acquired or innate immune cells, in vitro, although the mechanism for this is unclear. PGE2, TGF-B1, HGF and others are reported to be key molecules for their function [19]. It has also been suggested that cell-cell direct contact is needed. They differentiate into fibroblasts; chondroid, muscle, tendon, bone blasts and endothelial cells. In bone marrow, they construct the environment. MSCs are considered be have immunogenicity, displaying low expression levels of human leukocyte antigen (HLA) major histocompatibility complex (MHC) class I and no expression of costimulatory molecules. In vitro studies have demonstrated that MSCs do not elicit a proliferative response from allogeneic lymphocytes [42]. This evidence supports the possibility of exploiting third party donor MSCs for therapeutic applications.

However, recent findings indicate that MSCs can function as APCs and activate immune responses under appropriate conditions [19, 43]. It has been hoped that MSCs would reach sites of inflammation, but evidence for this is lacking. Transfused MSCs are trapped in the lungs and then remain in the liver and spleen [42]. The possibility that some may reach sites of inflammation cannot be ruled out, but that action may be a paracrine function.

To some extent, concerns about the ectopic formation and transforming to malignancy during the passage of MSC remain [44].
Taken together, the mechanisms of MSC in acting against GVHD remain unclear. It is speculated that allogeneic MSCs can engraft in immunocompromised hosts or at immune-privileged sites but trigger an immune response in hosts with an intact immune system, resulting in elimination. On the other hand, elimination of allogeneic MSCs might be profitable. It is hoped that MSCs only temporarily suppress the immune system, thereby reducing the risk of infection, malignant transformation, or suppression of a graft-versus-tumor effect.

\section{GVHD}

Donor-versus-host alloreactivity may always be directed towards all recipient tissue and cells (GVHD) in addition to leukemia cells (GVL effect). GVHD has been classically divided into aGVHD, occurring within 100 days after transplantation, and chronic GVHD developing thereafter. However, aGVHD may occur beyond day 100 after HCT [3], often upon discontinuation of immunosuppression [45, 46]. In the new GVHD classification proposed by the National Institutes of Health Consensus Conference [47], aGVHD is defined as GVHD without features consistent with chronic GVHD, even occurring after day 100. aGVHD is a severe and potentially lifethreatening complication after transplantation. The most common primary therapy for aGVHD consists of methylprednisolone, $2 \mathrm{mg} / \mathrm{kg} / \mathrm{day}$ for 7-14 days, followed by gradual dose reduction if the GVHD improves. However, almost half of patients are thought to be resistant to this primary steroid therapy. A wide variety of second-line treatments such as ATG, MMF, daclizumab, alemuzmab, infliximab, pentostatin, etanercept, sirolimus, lowdose MTX and ECP, are reported from western [5-10, 48, 49] countries as well as Japan [12-18]. Mostly they found some merits but substantial portion of patients die because of high risk of infectious complications, immunosuppression-mediated toxicity and often incomplete GVHD remission. Further more recently endothelial damage in refractory GVHD has been well documented. Transplantation associated microangiopathy (TAM) may explain the steroid refractoriness in part $[50,51]$. In addition, immunosuppressive therapy for GVHD is associated with deterioration of the GVL effect, resulting in the risk of relapse of malignant disease. Thus the improved second line treatments are desired.

\section{MSCs for GVHD: Institution oriented studies}

Le Blanc first reported the transplantation of haploidentical mesenchymal stem cells in a patient with severe treatment-resistant grade IV aGVHD of the gut and liver, which resulted in a striking clinical response [20]. 
Following the initial success, European Group for Blood and Marrow Transplantation conducted a phase II clinical study aiming to assess whether mesenchymal stem cells could ameliorate GVHD after HSCT [24]. Fifty-five patients with steroid-resistant, severe, aGVHD received 1-3 infusions of bone-marrow derived mesenchymal stem cells from HLA-identical siblings, haploidentical donors, and third party donors $\left(1.4 \times 10^{6} / \mathrm{kg}\right)$. Three patients had recurrent malignant disease and one developed de-novo acute myeloid leukemia of the recipient origin. Complete responders had lower transplantation-related mortality 1 year after infusion than did patients with partial or no response (11 [37\%] of 30 vs. 18 [72\%] of $25 ; p=0.002)$ and higher overall survival 2 years after transplantation (16 [53\%] of 30 vs 4 [16\%] of $25 ; p=0.018$ ). They concluded that infusion of mesenchymal stem cells expanded in vitro, irrespective of the donor, and might be an effective therapy for patients with steroid-resistant, aGVHD. However, 33 patients had already received second-line therapy for aGVHD before MSCs infusion.

Introna et al reported that fourty patients with steroid refractory grade II to IV aGVHD received bone marrowderived MSCs [36]. Patients received a median of 3 MSCs infusions after having failed conventional immunosuppressive therapy. A median cell dose of $1.5 \times 10^{6} / \mathrm{kg}$ per infusion was administered. No acute toxicity was reported. Overall, 86 adverse events and serious adverse events were reported in the study, most of which $(72.1 \%)$ were of infectious nature. The overall response rate, measured at 28 days after the last MSCs injection, was $67.5 \%$, with $27.5 \%$ complete response. The latter was significantly more frequent in patients exhibiting grade II GVHD as compared with higher grades (61.5 vs. $11.1 \%, p=.002)$ and was borderline significant in children as compared with adults (46.7 vs. $16.0 \%, p=.065)$. Overall survival at 1 and 2 years from the first MSCs administration was 50.0 and $38.6 \%$, with a median survival time of 1.1 years. They concluded that MSCs can be safely administered on top of conventional immunosuppression for steroid resistant GVHD treatment.

Sanchez-Guijo et al reported that 25 patients with steroid refractory aGVHD received four infusions (days 1, 4, 11, 18) with $1.1 \times 10^{6} \mathrm{MSC} / \mathrm{kg}$ bone marrow-derived MSCs [37]. There were no adverse events related to the MSCs infusion in the 99 procedures performed. The response to MSCs at 60 days after the first dose was evaluable in 24 patients. Seventeen patients $(71 \%)$ responded (11 complete and 6 partial responses), with a median time to response of 28 days after the first MSCs dose, whereas 7 patients did not respond. They concluded that sequential cryopreserved third-party MSCs therapy is a safe procedure for patients with steroid-refractory aGVHD.

Wernicke et al reported the metaanalysis of 183 cases that nearly half patients with steroid refractory aGVHD had complete response [32]. Other reports have been from small clinical studies, including phase I or phase I/II studies to treat steroid refractory aGVHD with MSCs [20-39] (Table 1). Caution is needed when assessing the efficacy and adverse events of MSCs treatment because in all of these studies, second- or third line immunosuppressive agents in combination with MSCs were allowed.

\section{Clinical studies using MSCs made by Osiris Therapeutics, Inc. (Prochymal)}

Prochymal is MSCs manufactured by Osiris Therapeutics Inc. (Columbia, MD, USA) derived from bone marrow of unrelated healthy donor [52]. There are several reports on the effects of MSCs on patients with steroid-refractory GVHD [25, 30, 38].

Kebriaeir et al. reported that among 31 patients the CR rate was $77 \%$ and the survival rate in the patients who achieved CR was $88 \%$. They showed that there was no difference in effects between a high-dose $\left(8 \times 10^{6} / \mathrm{kg}\right)$ and low-dose $\left(2 \times 10^{6} / \mathrm{kg}\right)$ [25]. Prasad et al. [30] showed the efficacy of MSCs for pediatric patients with severe refractory aGVHD. Most patients received MSCs at a dose of $2 \times 10^{8}$ cells $/ \mathrm{kg}$.

From the favorable results in these two studies, Osiris conducted a double-blind randomized placebo-controlled phase III study to treat steroid-refractory acute GVHD in the United States, Canada, and Australia [52-54]. Patients were randomized at a 2:1 ratio for either MSCs or a placebo. MSC was given in a dose of $2 \times 10^{6} / \mathrm{kg}$ twice a week for 4 weeks, for a total 8 times. It should be noted that most patients had already received a second-line therapy before MSC therapy. This trial enrolled 260 patients. The primary endpoint was durable CR for 28 days. Unfortunately, the phase III trial did not prove the superiority of MSCs over the placebo (MSCs $35 \%$ vs. placebo $30 \%$ ). However, subpopulation analysis at day 100 showed that MSCs significantly improved the response in liver aGVHD (76 vs. $47 \%$ ) and gastrointestinal aGVHD (82 vs. $68 \%$ ), especially in children (71 vs. $50 \%$ ). Infection rates were not different between the MSCs and placebo groups. Rates of severe adverse effects associated with MSCs administration were not different in the two arms. MSCs are now approved for use in pediatric steroidrefractory aGVHD in Canada and New Zealand as a cellbased medicine [51].

\section{Prochymal studies in Japan}

JCR Pharmaceutical Co. Ltd. conducted a phase I/II clinical study [40]. At that time, it was anticipated that MSCs would be approved by the FDA after the phase III study in the USA and bridging study style might be considered and that this 


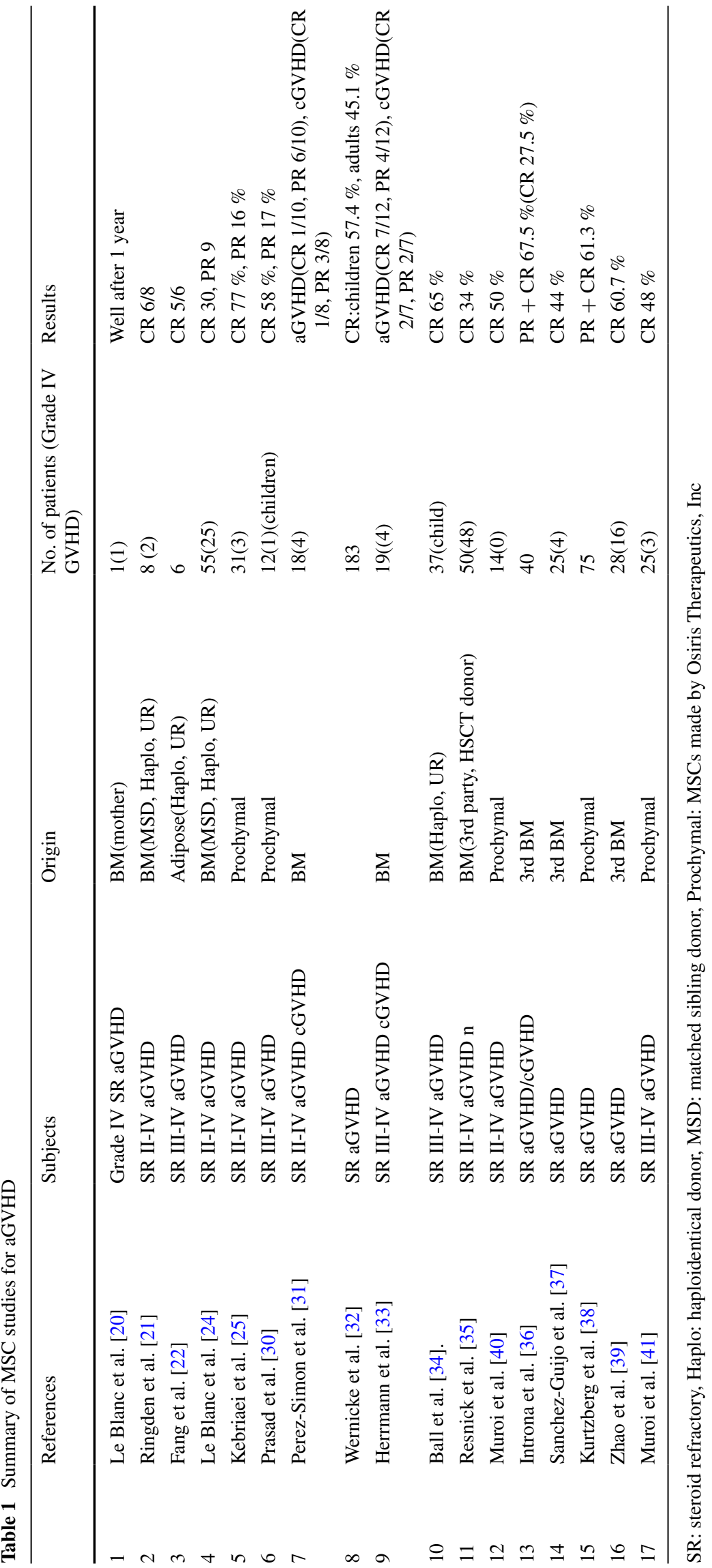


study was mainly to confirm safety and feasibility. However, the study failed to reach the endpoint and was not approved in the USA, and the PMDA requested that we perform a more rigorous study using only grade III-IV aGVHD [41].

In multicenter phase I/II study [40], 14 patients with hematological malignancies who suffered from grade II ( 9 patients) or III aGVHD [6] were treated. Affected organs were the gut (10 patients), skin (9 patients), and liver (3 patients). Seven patients had two involved organs. The median age was 52 years. No other second-line agents were given. MSCs were given at a dose of $2 \times 10^{6}$ cells/ $\mathrm{kg}$ in each infusion twice a week for 4 weeks. If needed, patients were continuously given MSCs weekly for an additional 4 weeks. By week 4, 13 of 14 patients (92.9\%) had responded to MSCs therapy with a complete response $(\mathrm{CR} ; n=8)$ or partial response (PR; $n=5)$. At 24 weeks, 11 patients (10 with $\mathrm{CR}$ and 1 with $\mathrm{PR}$ ) were alive. At 96 weeks, 8 patients were alive in CR. A total of 6 patients died, attributable to the following: underlying disease relapse (2 patients), breast cancer relapse (1), venoocclusive disease (1), ischemic cholangiopathy (1), and pneumonia (1). No clear adverse effects associated with MSCs infusion were observed. We concluded that third partyderived bone marrow MSCs may be safe and effective for patients with steroid-refractory aGVHD.

Following the phase I//II study a phase II/III study with the cells focused on steroid-refractory grade III or IV aGVHD was conducted [41]. Twenty-five patients (grade III, 22 patients and grade IV, three patients) were enrolled in this study. The cumulative incidence from the first MSC infusions to the achievement of CR is shown in Fig. 1. A $50 \% \mathrm{CR}$ was obtained around at 6 weeks after the first MSC infusions. The steroid dose from the start of MSC therapy to 24 weeks was plotted (Fig. 2). Steroid dose was reduced in about two-thirds at 4 weeks and about half at 8 weeks, thereafter nearing to the base line of $0 \mathrm{mg} /$ day. Overall survival after the first infusions of MSCs was plotted (Fig. 3). Taken together, our two clinical trials suggest MSCs to be effective for steroid-refractory aGVHD.

\section{Academic studies in Japan}

Currently, three clinical trials of MSCs for HSCT patients are listed or recruiting on the web site of the UMIN clinical trials registry. Hyogo College of Medicine is conducting a study entitled "Amniotic membrane-derived mesenchymal stromal cells for the treatment of steroid-resistant acute GVHD." Jichi Medical University is conducting a study entitled "Efficacy of mesenchymal stem cells for treatment of refractory acute GVHD after stem cell transplantation." Recruiting is already finished and they reported that 10 patients are enrolled and 3 patient received third

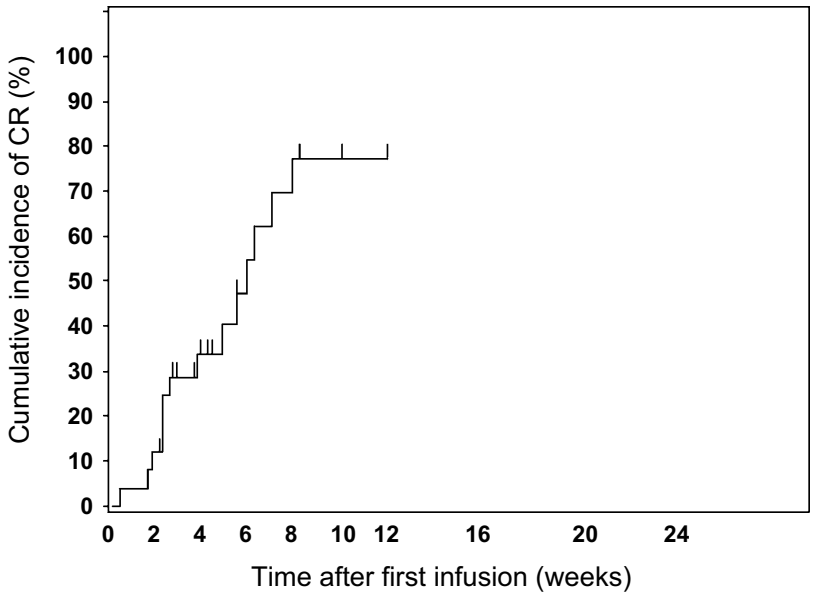

Fig. 1 Cumulative incidence of complete response after the first infusions of MSCs [41]

party MSCs resulting in mixed responses. They concluded that further studies are needed [55]. Nagoya University launched a clinical trial, but it is for engraftment not for GVHD. All in all, it seem to be still some distance from clinical practice in the HSCT centers in Japan.

\section{Insurance approval of TEMCELL ${ }^{\circledR}$ HS Injection}

Following the favorable outcome of clinical studies, the PMDA approved MSCs. The indication is, "acute graft-versus-host disease after hematopoietic stem cell transplantation." It is accompanied with the special precautions that "this product should be used only in a case where a sufficient therapeutic effect cannot be obtained even with steroid therapy," and "on using this product, the patients to be administered should be selected carefully after becoming fully aware of the severity of acute GVHD as well as the contents of the section of clinical studies and understanding the efficacy and safety of this product."

Also, a notification from the Minister's Secretariat Counsellor, Ministry of Health, Labor and Welfare (in charge of medical device/regenerative medicine review control) has been issued (http://www.jshct.com/pdf/2015925.pdf).

\section{Cost}

MSCs cost more than ten million yen (approximately $\$ 100,000)$ per course of MSCs therapy for refractory GVHD. From the database of the Japanese Data Center for Hematopoietic Cell Transplantation (JDCHCT), the number of cases of aGVHD more than the grade II is approximately 1000 and at least $40 \%$ are steroid refractory. If half of them are candidates for MSCs therapy, it would be at a total cost of $¥ 2.6$ billion. 


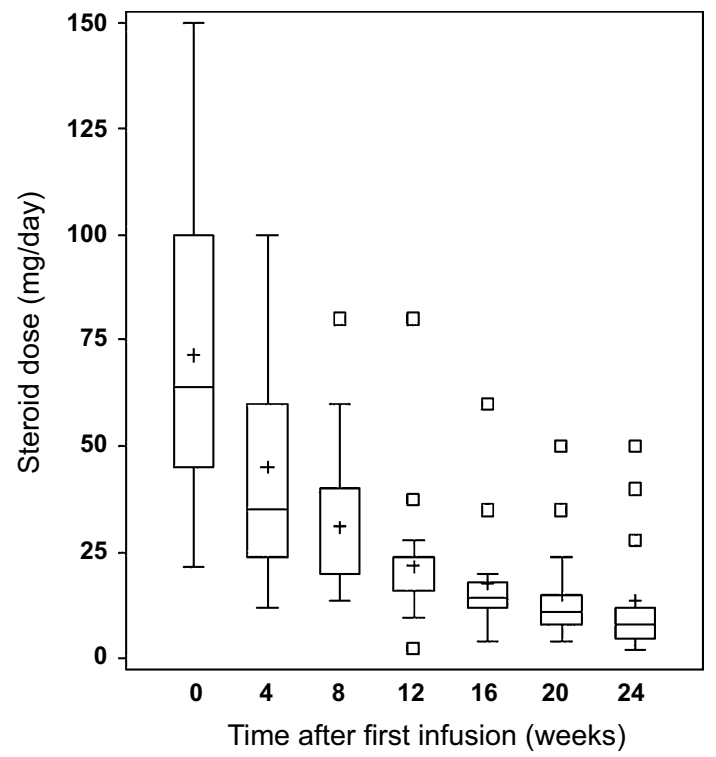

Fig. 2 Steroid doses after MSC administration displayed by the boxplot method. Plus signs and squares indicate mean and extreme outliers, respectively [41]

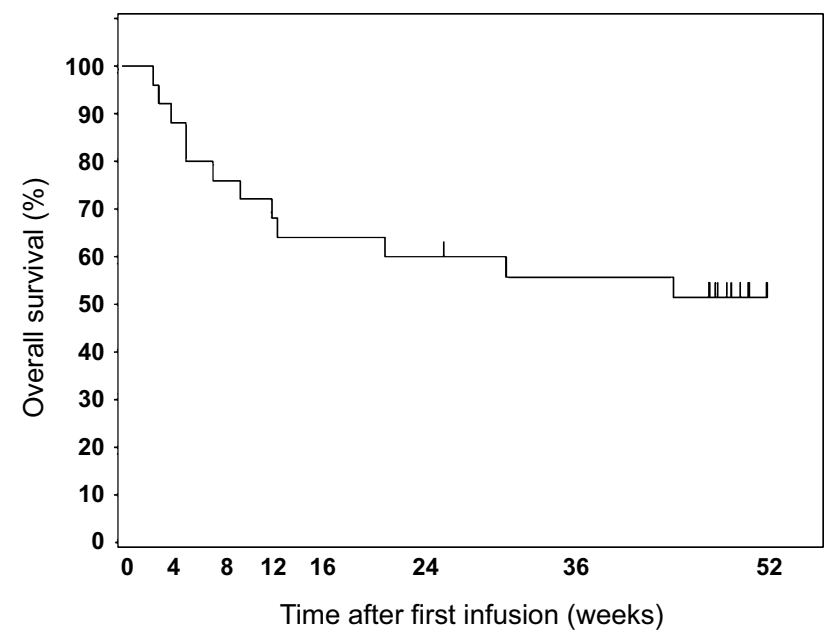

Fig. 3 Overall survival after the first infusions of MSCs. At 52 weeks, 12 patients $(48 \%)$ were alive [41]

\section{The methods of production}

The methods of production is open. Briefly, an aliquot of bone marrow obtained from healthy volunteers was cultured in a medium supplemented with $10 \%$ fetal bovine serum from New Zealand (Life Technologies, New York, USA). The fetal bovine serum products were free of bacteria, viruses, mycoplasma, and endotoxins in the checking tests. The products met standards for Code of Federal Regulations 9CFR113.53 and the United States Department of Agriculture. Adherent cells were expanded by culture and used as MSCs. Before freezing, cells were examined in the terms of MSCs characteristics [40]. Isolated cells showed positivity for CD73, CD90, CD105, and CD166 and negativity for CD34, CD45, and HLA-DR. The cells inhibited the mixed-lymphocyte reaction and differentiated to fat cells, chondrocytes, and osteoblasts. The cells had the ability to produce prostaglandin E2. Multicolor-fluorescence in situ hybridization showed that the cells had no chromosomal abnormalities. No infectious agents such as bacteria, mycoplasma, or viruses were detected in the supernatants of the cells or the cells themselves. No endotoxin was detected in the supernatant. Number of passage was not open to the public.

\section{Discussion}

\section{Clinical issues}

Several studies have demonstrated the merits of MSCs for steroid refractory aGVHD treatment. However, because a majority of patients had already received one or more immunosuppressant before MSCs administration, it is difficult to evaluate the effectiveness of MSCs. A commercially sponsored, randomized Phase III study in steroid-refractory acute GVHD (NCT00366145) apparently did not reach significance in its primary endpoint, failing to show a difference in complete response rate in those receiving MSCs. This study suggested that MSCs therapy might be more useful for certain groups of patients such as those with liver and gut GVHD or pediatric patients [53, 54]. It might be certain that in some patients MSCs is useful and only curable management.

\section{Scientific concerns}

As mentioned above, the evidence that MSCs reach sites of inflammation is lacking [42]. The mechanism for improvement of GVHD by MSCs remains unclear, although several in vitro studies have been reported. Transfused MSCs are trapped in the lungs, liver and spleen. The possibility that some may reach sites of inflammation cannot be ruled out, but that action may be a paracrine function. Further investigations are needed in clinical setting, e.g. immunohistochemical analysis of biopsy, autopsy specimens.

The donor source in these studies was heterogeneous and included autologous, related donor and unrelated healthy donor (including HLA mismatch third-party). MSCs sources are variable such as bone marrow, adipose tissue, placenta, amniotic fluid and cord blood. Some concerns about purity and cell function have been raised with regard to the production of MSCs in different institutes. Efficacy has apparently not depended on whether 
HLA-matched haploidentical or third party donor cells were used [24]. The age and gender of the donor may be a cause of variability in growth potential as well as culture conditions, such as choice of media and seeding density [56]. The number of MSCs infused, the number of MSCs infusions, and infusion intervals also varied among the clinical trials.

\section{Safety issues}

Manufacture under good manufacturing practices (GMP) is important in the prevention of contamination of products with microorganisms. In Japan, MSCs are produced according to GMP both in academic setting and in companies.

Because of the immunosuppressive effect of MSCs, it might be reasonable to expect that a smaller GVL effect could induce a recurrence of the treated hematologic malignancy in recipients treated with MSCs. Currently, however, there are no reports of such, although it must be admitted that the numbers are small.

Compounding the risk of opportunistic infection in an already heavily immune-deficient host is the immunosuppressive function of MSCs. Decreased immunoglobulin activity is reported in MSCs. There are also reports of increases in EBV-PTLP and fungal infections, and reports of increased occurrence of cancer. On the other hand, a German group has published an intriguing in vitro study of the antimicrobial effect of human and murine MSCs [57].

Histological studies of autopsies and tissues in patients who had received MSCs for steroid-refractory acute GVHD did not find any evidence of MSC-related malignancy nor ectopic bone formation [58]. As chromosomal changes leading to malignancy are possible but not shown in man. The expantion of cells for therapeutic use is considered important because of the potential risk of malignant transformation in culture through many passages $[59,60]$. The possibility of change in feature of MSC through passage is also unclear [61]. According to TEMCELL ${ }^{\circledR}$, the detailed number of passages is not available to the public.

\section{Economic issue}

The Japan pharmaceutical products trade deficit was $¥ 162$ billion in 2012. It estimated that MSCs treatment will increase the medical cost $¥ 2.6$ billion. Following, MSCs, clinical study of ECP (extracorporeal photopheresis) is running and that of CAR, cord blood cell expansion are now planning by pharmaceutical companies. Along with emerging molecular targeting drug, cell therapies are advancing at tremendous speeds with the increasement of medical cost.

\section{Future direction and perspective}

In just the field of HSCT, a fair number of academics in Japan are pursuing research with the aim of clinical applications of cell therapy. Academics have been making cell therapies for more than the past decade. There is a path laid out for academics that leads to insurance coverage for a medical technology. After they have completed an initial feasibility institutional clinical study, they can then move on to advance medical technology "Koudo Sennshinn Iryou". However, this is a very daunting process or at least it is time consuming, and over the past decade not a single treatment has reached this point in the field of hematopoietic stem cell transplantation

One other way forward is to work for pharmaceutical approval as a product for regenerative medicine, but this requires the steady continuation of research to support technical development and clinical trials by companies and academic support is needed. In this case, there are also points that need to be sorted out with regard to the profitability of companies that contract cell culture work and investment in companies when they aim to develop regenerative medicine products. Some of the basic technology for this has been patented by foreign companies and measures are also needed in terms of avoiding or adopting patents.

TEMCELL $^{\circledR}$ was approved by PMDA in September 2015. At first, it will be used only in the 20 institutes that were involved in the clinical studies. The government ask the company and JSHCT for comprehensive data collection. The total cost is estimating to be 2.6 billion. Japan's pharmaceutical products trade deficit was $¥ 162$ billion in 2012. Cell therapy and molecular targeting agents are increasing and there are some concerns about the trade deficit and increasing the medical costs are proposed. However, the most important issue is the development of effective treatment and supply to those patients who need them. It may be great undertaking to balance the benefit and cost.

Finally even though the clinical feasibly was confirmed in phase II studies, several concerns are remaining. Thus TEMCELL ${ }^{\circledR}$ should be used only in restricted well trained institutes and the patients should be selected carefully with informed consent regarding the severity of acute GVHD and the efficacy and safety of this product.

\section{Conclusion}

1. Most of the published trials have reported a favorable effect in acute GVHD, but no randomized phase III trial confirmed this.

2. The mechanism of how MSCs works for GVHD has not been clarified and the nature of MSCs after infusion remain unknown. 
3. MSCs (TEMCELL ${ }^{\circledR}$ ) is approved for severe GVHD by the Japanese PMDA, along with restricted institutions and data collection is being planned.

4. Registration of all patients in the post marketing study is mandatory and long term follow up to confirm the efficacy and adverse events is recommended.

5. Commercial MSCs is very expensive but have the merit of easy supply to larger numbers of patients and the practice field and constancy.

6. Academic production of MSCs are less expensive and have some advantages, and national strategies for developing new agents by collaboration between academics and companies are being promoted in Japan.

Acknowledgments The author thank Drs. Masafumi Ito, Yoshiyuki Takahashi, Yukiyasu Ozawa, Tetsuya Nishida, Toshihiro Soma, Yoshihiro Inamoto, and Hideo Harigae for profpund discussion and suggestions. Also many thanks to Drs. Naomi Kawashima and Yusuke Kagaya for peer review of this manuscript.

\section{Compliance with ethical standards}

Conflict of interest The author declares that he has no conflict of interest.

\section{References}

1. Gooley TA, Chien JW, Pergam SA, Hingorani S, Sorror ML, Boeckh M, et al. Reduced mortality after allogeneic hematopoietic cell transplantation. New Engl J Med. 2010;363:2091-3101.

2. Murata M. Prophylactic and therapeutic treatment of graft-versus-host disease in Japan. Int J Hematol. 2015;101:467-86.

3. Inamoto Y, Martin PJ, Storer BE, Mielcarek M, Storb RF, Carpenter PA. Response endpoints and failure-free survival after initial treatment for acute graft-versus-host disease. Haematologica. 2014;99(2):385-91.

4. Martin I, Ireland H, Baldomero H, Passweg J. The survey on cellular and engineered tissue therapies in Europe in 2012. Tissue Eng Part A. 2015;21(1-2):1-13.

5. MacMillan ML, Weisdorf DJ, Davies SM, DeFor TE, Burns LJ, Ramsay NK, et al. Early antithymocyte globulin therapy improves survival in patients with steroid-resistant acute graft-versus-host disease. Biol Blood Marrow Transpl. 2002;8(1):40-6.

6. Furlong $\mathrm{T}$, Martin $\mathrm{P}$, Flowers ME, Carnevale-Schianca $\mathrm{F}$, Yatscoff R, Chauncey $\mathrm{T}$, et al. Therapy with mycophenolate mofetil for refractory acute and chronic GVHD. Bone Marrow Transpl. 2009;44(11):739-48.

7. Willenbacher W, Basara N, Blau IW, Fauser AA, Kiehl MG. Treatment of steroid refractory acute and chronic graft-versushost disease with daclizumab. Br J Haematol. 2001;112(3):820-3.

8. Schub N, Gunther A, Schrauder A, Claviez A, Ehlert C, Gramatzki M, et al. Therapy of steroid-refractory acute GVHD with CD52 antibody alemtuzumab is effective. Bone Marrow Transpl. 2011;46(1):143-7.

9. Couriel D, Saliba R, Hicks K, Ippoliti C, de Lima M, Hosing C, et al. Tumor necrosis factor-alpha blockade for the treatment of acute GVHD. Blood. 2004;104(3):649-54.

10. Hoda D, Pidala J, Salgado-Vila N, Kim J, Perkins J, Bookout R, et al. Sirolimus for treatment of steroid-refractory acute graftversus-host disease. Bone Marrow Transpl. 2010;45(8):1347-51.
11. Park JH, Lee HJ, Kim SR, Song GW, Lee SK, Park SY, et al. Etanercept for steroid-refractory acute graft versus host disease following allogeneic hematopoietic stem cell transplantation. Korean J Intern Med. 2014;29(5):630-6.

12. Inagaki J, Fukano R, Kodama Y, Nishimura M, Shimokawa M, Okamura J. Safety and efficacy of low-dose methotrexate for pediatric patients with steroid-refractory acute graft-versus-host disease after hematopoietic stem cell transplantation. Ann Hematol. 2014;93(4):645-51.

13. Iyama S, Murase K, Sato T, Hashimoto A, Tatekoshi A, Horiguchi $\mathrm{H}$, et al. Narrowband ultraviolet B phototherapy ameliorates acute graft-versus-host disease by a mechanism involving in vivo expansion of CD4 + CD25 + Foxp3 + regulatory T cells. Int J Hematol. 2014;99(4):471-6.

14. Nishimoto M, Nakamae $H$, Koh H, Nakamae M, Hirose A, Hayashi Y, et al. Response-guided therapy for steroid-refractory acute GVHD starting with very-low-dose antithymocyte globulin. Exp Hematol. 2015;43(3):177-9.

15. Ohashi K, Tanaka Y, Mori S, Okuyama Y, Hiruma K, Akiyama $\mathrm{H}$, et al. Low-dose antithymocyte globulin for treatment of steroid-pulse-resistant acute graft-versus-host disease. Int J Hematol. 2003;77(1):99-102.

16. Onishi C, Ohashi K, Sawada T, Nakano M, Kobayashi T, Yamashita $\mathrm{T}$, et al. A high risk of life-threatening infectious complications in mycophenolate mofetil treatment for acute or chronic graft-versus-host disease. Int $\mathrm{J}$ Hematol. 2010;91(3):464-70.

17. Takami A, Mochizuki K, Okumura H, Ito S, Suga Y, Yamazaki $\mathrm{H}$, et al. Mycophenolate mofetil is effective and well tolerated in the treatment of refractory acute and chronic graft-versus-host disease. Int J Hematol. 2006;83(1):80-5.

18. Yamane T, Yamamura R, Aoyama Y, Nakamae H, Hasegawa T, Sakamoto C, et al. Infliximab for the treatment of severe steroid refractory acute graft-versus-host disease in three patients after allogeneic hematopoietic transplantation. Leuk Lymphoma. 2003;44(12):2095-7.

19. Salem HK, Thiemermann C. Mesenchymal stromal cells: current understanding and clinical status. Stem Cells. 2010;28(3):585-96.

20. Le Blanc K, Rasmusson I, Sundberg B, Gotherstrom C, Hassan M, Uzunel M, et al. Treatment of severe acute graft-versus-host disease with third party haploidentical mesenchymal stem cells. Lancet. 2004;363(9419):1439-41.

21. Ringden O, Uzunel M, Rasmusson I, Remberger M, Sundberg B, Lonnies H, et al. Mesenchymal stem cells for treatment of therapy-resistant graft-versus-host disease. Transplantation. 2006;81(10):1390-7.

22. Fang B, Song Y, Liao L, Zhang Y, Zhao RC. Favorable response to human adipose tissue-derived mesenchymal stem cells in steroid-refractory acute graft-versus-host disease. Transpl Proc. 2007;39(10):3358-62.

23. Muller I, Kordowich S, Holzwarth C, Isensee G, Lang P, Neunhoeffer F, et al. Application of multipotent mesenchymal stromal cells in pediatric patients following allogeneic stem cell transplantation. Blood Cells Mol Dis. 2008;40(1):25-32.

24. Le Blanc K, Frassoni F, Ball L, Locatelli F, Roelofs H, Lewis I, et al. Mesenchymal stem cells for treatment of steroid-resistant, severe, acute graft-versus-host disease: a phase II study. Lancet. 2008;371(9624):1579-86.

25. Kebriaei P, Isola L, Bahceci E, Holland K, Rowley S, McGuirk J, et al. Adult human mesenchymal stem cells added to corticosteroid therapy for the treatment of acute graft-versus-host disease. Biol Blood Marrow Transpl. 2009;15(7):804-11.

26. von Bonin M, Stolzel F, Goedecke A, Richter K, Wuschek N, Holig K, et al. Treatment of refractory acute GVHD with thirdparty MSC expanded in platelet lysate-containing medium. Bone Marrow Transpl. 2009;43(3):245-51. 
27. Lim JH, Lee MH, Yi HG, Kim CS, Kim JH, Song SU. Mesenchymal stromal cells for steroid-refractory acute graft-versus-host disease: a report of two cases. Int J Hematol. 2010;92(1):204-7.

28. Lucchini G, Introna M, Dander E, Rovelli A, Balduzzi A, Bonanomi S, et al. Platelet-lysate-expanded mesenchymal stromal cells as a salvage therapy for severe resistant graft-versus-host disease in a pediatric population. Biol Blood Marrow Transpl. 2010;16(9):1293-301.

29. Arima N, Nakamura F, Fukunaga A, Hirata H, Machida H, Kouno S, et al. Single intra-arterial injection of mesenchymal stromal cells for treatment of steroid-refractory acute graft-versus-host disease: a pilot study. Cytotherapy. 2010;12(2):265-8.

30. Prasad VK, Lucas KG, Kleiner GI, Talano JA, Jacobsohn D, Broadwater G, et al. Efficacy and safety of ex vivo cultured adult human mesenchymal stem cells (Prochymal) in pediatric patients with severe refractory acute graft-versus-host disease in a compassionate use study. Biol Blood Marrow Transpl. 2011;17(4):534-41.

31. Perez-Simon JA, Lopez-Villar O, Andreu EJ, Rifon J, Muntion $\mathrm{S}$, Diez Campelo M, et al. Mesenchymal stem cells expanded in vitro with human serum for the treatment of acute and chronic graft-versus-host disease: results of a phase I/II clinical trial. Haematologica. 2011;96(7):1072-6.

32. Wernicke CM, Grunewald TG, Juenger H, Kuci S, Kuci Z, Koehl $\mathrm{U}$, et al. Mesenchymal stromal cells for treatment of steroidrefractory GvHD: a review of the literature and two pediatric cases. Int Arch Med. 2011;4(1):27.

33. Herrmann R, Sturm M, Shaw K, Purtill D, Cooney J, Wright M, et al. Mesenchymal stromal cell therapy for steroid-refractory acute and chronic graft versus host disease: a phase 1 study. Int $\mathbf{J}$ Hematol. 2012;95(2):182-8.

34. Ball LM, Bernardo ME, Roelofs H, van Tol MJ, Contoli B, Zwaginga JJ, et al. Multiple infusions of mesenchymal stromal cells induce sustained remission in children with steroid-refractory, grade III-IV acute graft-versus-host disease. Br J Haematol. 2013;163(4):501-9.

35. Resnick IB, Barkats C, Shapira MY, Stepensky P, Bloom AI, Shimoni A, et al. Treatment of severe steroid resistant acute GVHD with mesenchymal stromal cells (MSC). Am J Blood Res. 2013;3(3):225-38.

36. Introna M, Lucchini G, Dander E, Galimberti S, Rovelli A, Balduzzi A, et al. Treatment of graft versus host disease with mesenchymal stromal cells: a phase I study on 40 adult and pediatric patients. Biol Blood Marrow Transpl. 2014;20(3):375-81.

37. Sanchez-Guijo F, Caballero-Velazquez T, Lopez-Villar O, Redondo A, Parody R, Martinez C, et al. Sequential third-party mesenchymal stromal cell therapy for refractory acute graft-versus-host disease. Biol Blood Marrow Transpl. 2014;20(10):1580-5.

38. Kurtzberg J, Prockop S, Teira P, Bittencourt H, Lewis V, Chan $\mathrm{KW}$, et al. Allogeneic human mesenchymal stem cell therapy (remestemcel-L, Prochymal) as a rescue agent for severe refractory acute graft-versus-host disease in pediatric patients. Biol Blood Marrow Transpl. 2014;20(2):229-35.

39. Zhao K, Lou R, Huang F, Peng Y, Jiang Z, Huang K, et al. Immunomodulation effects of mesenchymal stromal cells on acute graft-versus-host disease after hematopoietic stem cell transplantation. Biol Blood Marrow Transpl. 2015;21(1):97-104.

40. Muroi K, Miyamura K, Ohashi K, Murata M, Eto T, Kobayashi $\mathrm{N}$, et al. Unrelated allogeneic bone marrow-derived mesenchymal stem cells for steroid-refractory acute graft-versus-host disease: a phase I/II study. Int J Hematol. 2013;98(2):206-13.

41. Muroi K, Miyamura K, Okada M, Yamashita T, Murata M, Ishikawa $\mathrm{T}$, et al. Bone marrow-derived mesenchymal stem cells (JR-031) for steroid-refractory grade III or IV acute graft-versus-host disease: a phase II/III study. Int J hematol. 2015 [Epub ahead of print]
42. Nauta AJ, Fibbe WE. Immunomodulatory properties of mesenchymal stromal cells. Blood. 2007;110(10):3499-506.

43. Sundin M, Ringden O, Sundberg B, Nava S, Gotherstrom C, Le Blanc K. No alloantibodies against mesenchymal stromal cells, but presence of anti-fetal calf serum antibodies, after transplantation in allogeneic hematopoietic stem cell recipients. Haematologica. 2007;92(9):1208-15.

44. von Bahr L, Sundberg B, Lonnies L, Sander B, Karbach H, Hagglund $\mathrm{H}$, et al. Long-term complications, immunologic effects, and role of passage for outcome in mesenchymal stromal cell therapy. Biology of blood and marrow transplantation : journal of the American Society for Blood and Marrow Transplantation. 2012;18(4):557-64.

45. Baron F, Sandmaier BM. Chimerism and outcomes after allogeneic hematopoietic cell transplantation following nonmyeloablative conditioning. Leukemia. 2006;20(10):1690-700.

46. Childs R, Clave E, Contentin N, Jayasekera D, Hensel N, Leitman S, et al. Engraftment kinetics after nonmyeloablative allogeneic peripheral blood stem cell transplantation: full donor T-cell chimerism precedes alloimmune responses. Blood. 1999;94(9):3234-41.

47. Filipovich AH, Weisdorf D, Pavletic S, Socie G, Wingard JR, Lee SJ, et al. National Institutes of Health consensus development project on criteria for clinical trials in chronic graft-versushost disease: I. Diagnosis and staging working group report. Biol Blood Marrow Transplant J Am Soc Blood Marrow Transplant. 2005;11(12):945-56.

48. Pidala J, Kim J, Roman-Diaz J, Shapiro J, Nishihori T, Bookout $\mathrm{R}$, et al. Pentostatin as rescue therapy for glucocorticoid-refractory acute and chronic graft-versus-host disease. Ann Transplant Q Polish Transplant Soc. 2010;15(4):21-9.

49. Pidala J, Kim J, Perkins J, Field T, Fernandez H, Perez L, et al. Mycophenolate mofetil for the management of steroidrefractory acute graft vs host disease. Bone Marrow Transpl. 2010;45(5):919-24.

50. Luft T, Dietrich S, Falk C, Conzelmann M, Hess M, Benner A, et al. Steroid-refractory GVHD: T-cell attack within a vulnerable endothelial system. Blood. 2011;118(6):1685-92.

51. Ueda N, Chihara D, Kohno A, Tatekawa S, Ozeki K, Watamoto $\mathrm{K}$, et al. Predictive value of circulating angiopoietin- 2 for endothelial damage-related complications in allogeneic hematopoietic stem cell transplantation. Biology of blood and marrow transplantation : journal of the American Society for Blood and Marrow Transplantation. 2014;20(9):1335-40.

52. Daly A., Remestemcel-L, the first cellular therapy product for the treatment of graft-versus-host disease. Drugs Today (Barc). 2012;48(12):773-83.

53. Martin PJ UJ, Soiffer RJ, Klingemann H, Waller EK, Daly AS, et al. Prochymal improves response rates in patients with steroidrefractory acute graft versus host disease (SR-GVHD) involving the liver and gut: results of a randomized, placebo-controlled, multicenter phase III trial in GVHD. Biol Blood Marrow Transplant. 2010;16(Supplement 2):S169-70.

54. Szabolcs PVG, Locatelli F, Kleiner G, Talano J, Nemecek E, et al. Treatment of steroid-refractory acute GVHD with mesenchymal stem cells improves outcomes in pediatric patients; results of the pediatric subset in a phase III randomized, placebocontrolled study. Biol Blood Marrow Transplant. 2010;16(Supplement 2):S298.

55. Sato K, Muroi K, Oka S, Sasazaki M, Hosonuma R, Ozaki K, Fujiwara SI, Oh I, Matsuyama T, Ohmine K, Suzuki T, Mori M, Nagai T, Ozawa K. A Pilot Study of A Novel Therapy Using Mesenchymal Stromal Cells for Steroid-Resistant Graft-VersusHost Disease. Jichi Med Univ J. 2011;34:149-57

56. Fossett E, Khan WS. Optimising human mesenchymal stem cell numbers for clinical application: a literature review. Stem Cells Int. 2012;2012:465259. 
57. Meisel R, Brockers S, Heseler K, Degistirici O, Bulle H, Woite $\mathrm{C}$, et al. Human but not murine multipotent mesenchymal stromal cells exhibit broad-spectrum antimicrobial effector function mediated by indoleamine 2,3-dioxygenase. Leukemia. 2011;25(4):648-54.

58. von Bahr L, Batsis I, Moll G, Hagg M, Szakos A, Sundberg B, et al. Analysis of tissues following mesenchymal stromal cell therapy in humans indicates limited long-term engraftment and no ectopic tissue formation. Stem Cells. 2012;30(7):1575-8.

59. Casiraghi F, Remuzzi G, Abbate M, Perico N. Multipotent mesenchymal stromal cell therapy and risk of malignancies. Stem cell reviews. 2013;9(1):65-79.
60. Prockop DJ. Defining the probability that a cell therapy will produce a malignancy. Mol Ther J Am Soc Gene Ther. 2010;18(7):1249-50.

61. Moll G, Rasmusson-Duprez I, von Bahr L, Connolly-Andersen AM, Elgue G, Funke L, et al. Are therapeutic human mesenchymal stromal cells compatible with human blood? Stem cells. 2012;30(7):1565-74. 